\title{
VAREJO: DESAFIOS E OPORTUNIDADES EM MERCADOS EMERGENTES
}

0 tema do $5^{\circ}$ Congresso Latino-Americano de Varejo (CLAV-2012), realizado na FGV-EAESP em 25 e 26 de outubro de 2012, foi "Varejo: Desafios e Oportunidades em Mercados Emergentes". Desde 2008, quando foi realizado o primeiro CLAV, as características principais do congresso têm-se fortalecido: i) um evento em que se discutem cientificamente temas de varejo com implicações para mercados emergentes (como também foram os temas no CLAV-2008 e CLAV-2013); ii) um evento em que se discutem temas de vanguarda para o varejo (como no CLAV-2009, cujo tema foi a questão do valor e eficiência em estratégias para cenários turbulentos, e no CLAV2011, em que foi discutida a influência das novas mídias e redes sociais no varejo); iii) um evento em que a aplicabilidade e relevância das pesquisas são muito valorizadas (o tema do CLAV-2010 foi “Competitividade no Varejo: Teoria e Relevância Prática”), buscando-se sempre a interação entre profissionais de mercado e acadêmicos, seja no formato de painéis de executivos, como uma maneira de se discutirem as demandas de conhecimento do mercado, ou com a submissão de artigos executivos, como no caso do CLAV-2013; iv) um evento que prestigia não apenas os pesquisadores e palestrantes experientes da academia mas também aqueles que estão iniciando, com o tradicional consórcio doutoral e banca de iniciação científica para alunos de graduação; e v) um evento que busca a internacionalização: ao longo destes anos, o CLAV tem priorizado a vinda de pesquisadores reconhecidos na academia internacional, como editores de periódicos top de varejo, e a atração de artigos estrangeiros, com sessões de apresentação exclusivamente em inglês. Atualmente, o CLAV recebe apoio das três principais agências de fomento brasileiras: CAPES, CNPq e FAPESP.

\section{MERCADOS EMERGENTES}

Mercado emergente é definido como uma economia em crescimento, com uma renda per capita de baixa a média (ARNOLD e QUELCH. 1998), cujos países integrantes representam um grande mercado potencial para as empresas. Considerando apenas os BRICS (Brasil, Rússia, Índia, Chi-

\section{EDGARD BARKI}

Professor da Escola de Administração de Empresas de São Paulo, Fundação Getulio Vargas São Paulo - SP, Brasil

\section{DELANE BOTELHO}

Professor da Escola de

Administração de Empresas de São Paulo, Fundação Getulio Vargas São Paulo - SP, Brasil

\section{JURACY PARENTE}

Professor da Escola de

Administração de Empresas de São Paulo, Fundação Getulio Vargas São Paulo - SP, Brasil na e África do Sul), tem-se uma população de quase três bilhões de pessoas e um PIB de aproximadamente US\$14,6 trilhões (THE WORLD BANK, 2013). Esses mercados são caracterizados por uma enorme população considerada como da base da pirâmide, composta de pessoas que vivem com menos de US\$ 4 por dia (PRAHALAD, 2005). Por outro lado, há uma relativamente pequena parcela de uma população mais afluente e que também tem um impacto significativo no consumo. Não existe consenso entre os pesquisadores sobre as fronteiras da definição dos rendimentos da base da pirâmide, mas o World Economic Forum (2009) classificou os consumidores de baixa renda em três grupos: lowest (cerca de um bilhão de pessoas com ganho diário de menos de US\$1), middle (cerca de 1,6 bilhão de pessoas com renda diária entre US\$ 1 e US\$2) e top (cerca de 1,2 bilhão de pessoas com renda média diária entre US\$ 2 e US\$ 8).

A rápida expansão do poder de compra de países como Brasil, China e Índia está transformando essas regiões nos mercados líderes para varejo e bens de consumo. Na maioria dos países do mundo desenvolvido, o crescimento no médio prazo será baixo, e o crescimento de 
fato ocorrerá principalmente nos mercados emergentes. Estudo conduzido por Roxburg, Lund e Piotrowski (2011) revela que a maior parte do crescimento do mercado mundial ocorrerá nas áreas urbanas dos países emergentes, com crescimento significativo das cidades africanas e asiáticas. Além da expansão populacional, há o rápido desenvolvimento, nessas áreas, de uma nova "baixa classe média urbana", com uma renda média per capita diária superior a US\$10. Em 2011, os mercados emergentes também responderam por quase metade (24) das 50 empresas com crescimento mais rápido (DELOITTE, 2013).

Para atuar e distribuir produtos e serviços em mercados na base da pirâmide, as empresas enfrentam uma série de desafios, sendo o acesso a essa população considerado uma das principais dificuldades. Comparados com países mais desenvolvidos, os mercados de baixa renda, em geral, são caracterizados por: grande capilaridade do mercado, existência de pequenas empresas não profissionalizadas e informais; falta de infraestrutura e altos custos de transporte, canais de distribuição e comunicação mais limitados, estruturas políticas e sociais menos maduras (ARNOLD e QUELCH, 1998; DE SOTO, 2000).

Os mercados emergentes possuem algumas outras características básicas (SHETH, 2011):

a. Heterogeneidade do mercado: enquanto os mercados desenvolvidos são mais homogêneos e globais, os mercados emergentes são heterogêneos e muito mais locais, sendo relevante uma visão mercadológica mais apurada das diferenças existentes entre os vários mercados. Por exemplo, apesar de Índia, China, África do Sul e Brasil serem considerados países emergentes, existem algumas diferenças marcantes entre eles, que também se refletem nos níveis de modernidade do varejo em cada um.

b. Governança sociopolítica: os mercados emergentes tendem a ter uma enorme influência de instituições sociopolíticas, que incluem religião, governo, grupos empresariais, organizações não governamentais (ONGs) e comunidade local.

c. Competição com produtos e empresas locais: há uma competitividade intensa entre as empresas/marcas globais e as marcas locais (KHANNA e PALEPU, 2006).

d. Necessidade de inovação pela falta crônica de recursos: há uma grande improvisação nos mercados emergentes, que pode ser vista como uma fonte de inovação de produtos de qualidade e de baixo custo, em uma perspectiva próxima da inovação reversa (desenvolver ideias em um mercado emergente e fazer com que sejam aplicadas também em mercados desenvolvidos) (IMMELT, GOVINDARAJAN, TRIMBLE, 2009). e. Infraestrutura inadequada: além da inadequação de estradas, aeroportos e infraestrutura básica, há uma ausência de sistemas regulatórios de propriedade eficazes (DE SOTO, 2000). Como a estrutura varejista é fortemente determinada pelo contexto local, as características variam de acordo com as condições econômicas, sociais e institucionais do mercado em que o varejo atua. Os países emergentes mostram grande variação nessas condições, devido aos seus diversos estágios de desenvolvimento e de renda.

Tais características mostram a relevância de se entenderem as necessidades dos consumidores nesses mercados e criar ou adaptar as estratégias para a realidade, nem sempre ideal, em que as empresas atuam. O varejo desempenha um papel de grande relevância nesse contexto, primeiro, por ser 0 principal elo para oferecer acesso à população, e, segundo, por ser um dos setores da economia que melhor conseguem adaptar-se às necessidades de cada localidade.

Com dados de gêneros alimentícios de 2011, os mercados emergentes apresentam uma estrutura de varejo que varia de predominantemente tradicional (que engloba pequenas mercearias familiares, lojinhas independentes e feiras livres) a predominantemente moderna (que inclui hipermercados, supermercados e lojas de conveniência) (DIAZ, MAGNI, POH, 2012):

1. Predominantemente tradicional: mais de $60 \%$ das vendas em varejo tradicional. A Índia, por exemplo, apresenta apenas $2 \%$ das vendas provenientes do varejo moderno;

2. Em transição: 40-50\% das vendas no varejo moderno, com crescimento significativo dessa modalidade nos últimos cinco anos. O Brasil encontra-se nessa classificação, com tendência rápida a tornar-se predominantemente moderno, com cerca de 50\% das vendas provenientes desse tipo de varejo;

3. Predominantemente moderno: $50 \%$ ou mais das vendas na classificação de varejo moderno. A China apresenta $62 \%$ das vendas de alimentos na modalidade varejo moderno.

Além de o Brasil apresentar uma renda per capita superior (U\$ 12,1 mil) à de países como China (US\$ 8,7 mil), Índia (US\$ 3,8 mil) e África do Sul (US\$11,6 mil), outra razão que contribui para a maior maturidade do varejo brasileiro está associada à predominância urbana do País ( $87 \%$ da população vive em áreas urbanas, comparado com 32\% na Índia, 51\% na China e $62 \%$ na África do Sul). O Brasil apresenta, também, apelos específicos para a atração de varejistas internacionais, como a própria renda per capita e a tendência rápida do formato de varejo moderno. Em estudos de comparação entre 
países, tais variáveis são chave para a compreensão das diferenças nos mercados. Para os fabricantes que atuam nesses mercados emergentes, é importante se prepararem para conviver simultaneamente com os formatos tradicional e moderno de varejo, ainda por um longo período. Muitos deles têm que se relacionar com milhares de distribuidores e atacadistas, que, muitas vezes, se esforçam para cumprir as metas ou estratégias de marca do fabricante para influenciar o comportamento dos varejistas. A consolidação de poucos distribuidores pode ser, portanto, importante para grandes players da indústria em mercados emergentes (DELOITTE, 2010). Para os acadêmicos, é essencial entender as especificidades de certas variáveis, principalmente aquelas relacionadas ao comportamento do consumidor e às estratégias das empresas varejistas, nesses diferentes formatos de varejo, e das características do relacionamento indústria-distribuidor-varejo, nos diversos mercados.

Algumas características dos mercados emergentes podem ter implicações diretas sobre como o varejo funciona nesses países, em relação aos países desenvolvidos, o que demanda um olhar atento do pesquisador do varejo, principalmente quando são feitas pesquisas comparativas entre países e regiões. Como já tem sido reconhecido em outros estudos sobre varejo em países emergentes (AMINE e LAZZAOUI, 2011), existe um significativo contraste entre os hábitos de compra e a estrutura de varejo entre os consumidores de alta e de baixa renda. No Brasil, por exemplo, as classes média e alta realizam suas compras predominantemente em grandes redes de supermercados de grupos globais ou nacionais e em bem-estruturados shopping centers. Os consumidores de baixa renda, entretanto, costumam se abastecer em varejistas menores e locais, e nos pouco confortáveis polos varejistas de rua, com diferentes níveis de modernização (PARENTE e outros, 2012).

\section{Perspectiva integrada para pesquisa em varejo em mercados emergentes}

Grewal e Levy (2009) analisaram como a pesquisa em varejo (e tópicos relacionados) evoluiu entre 2001 e 2007, e identificaram os seguintes temas predominantes: crescimento da internet e do e-commerce, branding e fidelidade do consumidor, estratégias de sucesso em serviços e questões de comportamento relacionadas à precificação e escolha de lojas. As características dos mercados emergentes levantadas por Sheth (2011) e os temas relevantes do varejo discutidos por Grewal e Levy (2009) oferecem uma visão integrada e complementar que ajuda a definir alguns dos desafios de pesquisa para o campo de varejo em mercados emergentes.
0 crescimento da internet e e-commerce é um fenômeno mundial que também afeta fortemente os países emergentes. 0 varejo tem se dinamizado e buscado soluções inovadoras como $m$-commerce, omni channel e C 2 C commerce, como o realizado pelo varejista Magazine Luiza, por meio das redes sociais. A característica multicanal no varejo engloba o comércio eletrônico móvel, que contribui, atualmente, com 5,1\% das vendas totais do varejo global e crescerá exponencialmente até alcançar de $17 \%$ a $21 \%$ (entre US\$ 628 bilhões e US\$ 752 bilhões) em vendas totais em 2016 (DIAZ, MAGNI, POH, 2013). Pelo próprio ambiente, com uma infraestrutura inadequada, a necessidade de inovação é grande nos países emergentes, por isso surgem conceitos, como o da inovação reversa (IMMELT, GOVINDARAJAN, TRIMBLE, 2009), que podem ser usados no ambiente de internet e também demandam pesquisas nesses países.

Quando se discute a questão de fidelidade do consumidor da base da pirâmide de mercados emergentes, há um mito de que esse consumidor busca sempre e apenas o menor preço possível ou a melhor promoção (SIMANIS, 2012), no entanto esse consumidor pode ser menos sensível ao preço do que se imagina, pois também busca valor (BARKI e PARENTE, 2006). Os varejistas locais, em geral, conseguem ter essa percepção e criam soluções mais próximas das necessidades dos consumidores, dedicando-se a atributos mais emocionais (PASWAN, PINEDA, RAMIREZ, 2010). Nessa lógica, tornam-se essenciais serviços básicos como empacotadores em supermercados, funcionários atenciosos e bem-treinados e ambiente de loja agradável, que podem passar a ser vistos como diferenciais competitivos. O fato de os varejistas locais oferecerem muitos desses serviços, que, às vezes, os grandes varejistas não proporcionam tão adequadamente, reforça a tese de que as empresas locais, muitas vezes, conseguem ser mais competentes do que as multinacionais (BHATTACHARYA e MICHAEL, 2008). Tal fenômeno pode ser mais bem compreendido no Brasil e na América Latina, com pesquisas dedicadas à comparação das estratégias varejistas de grandes empresas multinacionais e de pequenos varejistas locais.

Quanto às questões de comportamento relacionadas à precificação e escolha de lojas, algumas características do Brasil têm apelo ainda maior para os pesquisadores. Por exemplo, as vendas parceladas em cartões de crédito, em até 12 ou 24 vezes, são comuns, o que pode ser um tema fértil para testar e comparar modelos de contabilidade mental sobre a estruturação de preços pelos varejistas, e compreender fatores que afetam o processo de decisão do shopper brasileiro, como esquemas de processamento de informação, memória, envolvimento, atitudes e afeto que influenciam as escolhas. 
Dessa forma, é possível identificar alguns desafios que os mercados emergentes apresentam aos varejistas e à pesquisa no varejo. 0 primeiro deles é a competição entre empresas locais e grandes redes, disputa que afeta diretamente a lealdade e a escolha do consumidor; o segundo é a dificuldade de acesso a populações mais distantes ou em locais menos seguros; o terceiro é a heterogeneidade dos mercados, que exige uma atuação muito mais local; e o quarto é a dificuldade de encontrar mão de obra qualificada, sendo o treinamento e políticas de retenção muito relevantes. Algumas oportunidades surgem nesse contexto. Uma delas é o entendimento das peculiaridades do consumidor dos mercados emergentes, com toda a sua heterogeneidade, para a adoção de estratégias mais adequadas. Uma segunda oportunidade é a diferenciação baseada em serviços com uma ênfase especial na qualificação dos funcionários. Outra oportunidade é a busca de inovação, trabalhando-se mais intensamente os conceitos de multicanal e omni channel. Por fim, também é uma oportunidade a atuação conjunta entre fornecedores e varejistas, com grandes fornecedores intensificando o apoio a pequenos varejistas locais, que podem ser importantes canais de distribuição, e grandes varejistas trabalhando mais ativamente com pequenos fornecedores locais, que têm maior entendimento das necessidades da população de seu entorno.

Os desafios e oportunidades para pesquisa em varejo também são enormes. Muitos dos temas tratados acima podem ser abordados de maneira inovadora na pesquisa brasileira e latino-americana. Por exemplo, um volume enorme de dados (voláteis ou não) é produzido pelas empresas varejistas e pela indústria diariamente, porém poucos desses dados são analisados pela academia nesses países, ao contrário do que ocorre em países desenvolvidos. Isso é uma oportunidade para pesquisadores, principalmente aqueles interessados na área de modelagem em marketing, com uso de dados em painel e/ ou escaneados. Muitos desses dados provêm de ambientes de redes sociais, o que permite a compreensão de novas mídias sob a ótica de modelling. Outra abordagem que começa a chamar a atenção para entender fenômenos de comportamento de compra e consumo com implicações para o varejo é o uso de neurociência, permitindo uma perspectiva inovadora para a compreensão do comportamento humano, em geral, e do shopper, em específico. Por fim, o varejo em mercados emergentes carece de estudos sobre a interface entre marketing e finanças, com o uso de métricas mais apropriadas a esse mercado. Há demanda sobre o conhecimento e desenvolvimento de novas métricas aplicadas a esse contexto de varejo, e pesquisas assim são muito bem-vindas em congressos científicos como o CLAV.

\section{FÓRUM DE VAREJO}

Como já é de costume, os melhores artigos do CLAV-2012 em avaliação double blind review são considerados para publicação no Fórum RAE de Varejo. O presente fórum discute muitos dos assuntos relacionados às características dos mercados emergentes e aos temas mais relevantes ao varejo mundial, adaptados à realidade dos mercados emergentes. Três artigos discutem aspectos de comportamento do consumidor, dois relacionados a segmentos específicos (plus size e idosos) e outro relacionado à comunicação boca a boca. 0 artigo "O peso do varejo, o peso no varejo e a identidade: uma análise de consumidoras plus size", dos autores Maria Carolina Zanetti, Eliane Pereira Zamith Brito, Carlos Eduardo Lourenço, explora como o estigma e a escassez no varejo afetam os projetos de identidade de consumidoras plus size e como essas consumidoras contornam a escassez para tornar reais seus eu-estendidos desejados. 0 varejo, ao mesmo tempo que reforça a estigmatização por meio de discursos transmitidos e promove a exclusão dos estigmatizados, também traz possíveis soluções, restringindo ou possibilitando a materialização dos objetos que constituem o eu-estendido. No artigo "O novo consumidor idoso: identificação dos atributos varejistas relevantes e sua influência na lealdade", Evandro Luiz Lopes, Eduardo Garcia, Monica Aparecida Schiavo, Valdirene Mendes dos Santos partem do pressuposto de que o envelhecimento da população brasileira influencia seus hábitos de consumo e identificam atributos relevantes de uma loja varejista que afetam a lealdade dos consumidores idosos. Desenvolvem e testam um modelo estrutural, e uma das principais conclusões é que a lealdade dos idosos na amostra esteve mais ancorada nos aspectos de cordialidade e simpatia do que nos aspectos de agilidade e rapidez. No artigo "Personalidade e boca a boca: propensão ao envio e recebimento de informações”, Kenny Basso, Danubia Reck e Eduardo Rech avaliam a relação entre traços de personalidade e disposição para o boca a boca, evidenciando traços individuais que podem ser responsáveis por desencadear comportamentos de póscompra. Outro desafio dos mercados emergentes é a dificuldade com mão de obra, ainda mais relevante no varejo. No artigo "Determinantes do desempenho empresarial e das vendas cruzadas no varejo", Valter Afonso Vieira, David Pires, Ronie Galeano identificam variáveis preditoras da equipe de vendas que determinam o desempenho empresarial e as vendas cruzadas. As estimativas foram feitas regredindo as variáveis exógenas sobre as variáveis venda cruzada e desempenho empresarial.

Como dito anteriormente, há uma competição intensa entre empresas varejistas e marcas locais e globais. Muitos pequenos varejistas apresentam diversas vantagens competitivas 
em relação aos grandes grupos, mas ainda sofrem com um relacionamento menos intenso com os grandes fornecedores. Leandro Angotti Guissoni, Matheus Alberto Consoli, Jonny Mateus Rodrigues, no artigo “Is category management in small supermarkets worth the effort?", analisam os resultados de uma iniciativa de gerenciamento por categoria em pequenos varejistas de bairro, a partir de uma perspectiva da indústria, contrapon-

\section{REFERÊNCIAS}

AMINE, A; LAZZAOUI, N. Shoppers' reactions to modern food retailing systems in an emerging country: the case of Morocco. International Journal of Retail \& Distribution Management, v. 39, n. 8, p. 562-581, 2011.

ARNOLD, D. J; QUELCH, J. A. New strategies in emerging markets. Sloan Management Review, v. 40, n. 1, p. 7-20, 1998.

BARKI, E; PARENTE, J. Consumer behaviour of the base of the pyramid market in Brazil. Greener Management International, V. 2006, N.56, p. 11-23, 2006

BHATTACHARYA, A. K; MICHAEL, D. C. How local companies keep multinationals at bay. Harvard Business Review, V.86, N.3, p. 85-95, 2008.

DE SOTO, $\mathrm{H}$. The mystery of capital: why capitalism triumphs in the West and fails everywhere else. New York: Basic Books, 2000.

DELOITTE. Hidden heroes: emerging retail markets beyond China, Relatório Deloitte, 2010.

DELOITTE. Os poderosos do varejo global: sem fronteiras em um ambiente multicanal. Relatório Deloitte, 2013.

DIAZ, A; MAGNI, M; POH, F. From Oxcart to Wal-Mart: four keys to reaching emerging-market consumers. McKinsey Quarterly, N. 4, p. 58-67, 2012.

GREWAL, D; LEVY, M. Emerging issues in retailing research. Journal of Retailing. v. 85, n. 4, p. 522-526, 2009. do a literatura tradicional, em que a maioria das pesquisas investiga os efeitos do gerenciamento por categoria de um ponto de vista de implementação varejista, principalmente em mercados desenvolvidos e em varejistas de grande porte. Os resultados mostram um impacto positivo do gerenciamento de categoria nas vendas e na participação de mercado dessas pequenas lojas.

IMMELT J. R; GOVINDARAJAN, V; TRIMBLE, C. How GE is disrupting itself. Harvard Business Review, V.87, N.10, p. 56-65, 2009.

KHANNA, T; PALEPU, K. G. Emerging giants: building world-class companies in developing countries. Harvard Business Review, V.83, N.2, p. 60-69, 2006.

PARENTE, J; BRANDÃO, M; MIOTTO, A; PLUTARCO, F. Polos varejistas de rua ou shopping centers? Comparando as preferências da baixa renda. BBR-Brazilian Business Review, Edição Especial BBR Conference, p. 162189,2012

PASWAN, A; PINEDA, M. de los D. S; RAMIREZ, F. C. S. Small versus large retail stores in an emerging market-Mexico. Journal of Business Research, v. 63, n. 7, p. 667-672, 2010.

PRAHALAD, C. K. The fortune at the bottom of the pyramid. Upper Saddle River: Wharton School, 2005.

ROXBURGH, C; LUND, S; PIOTROWSKI, J. Urban world: mapping the economic power of cities. Relatório McKinsey Global Institute, 2011.

SHETH, J. N. Impact of emerging markets on marketing: rethinking existing perspectives and practices. Journal of Marketing, V. 75, N.4, p. 166-182, 2011.

SIMANIS, E. Reality check at the bottom of the pyramid. Harvard Business Review, p. 1-6, 2012.

THE WORLD BANK Countries and economies. Disponível em: http:// data.worldbank.org/country. Acesso em 19.09.2013.

WORLD ECONOMIC FORUM. The next billions: unleashing business potential in untapped markets. Report 150109, 2009. 